\title{
Robust motifs in 2-phenylethylammonium and related tetrahalometallates $\dagger$
}

\author{
Melanie Rademeyer, ${ }^{* a}$ Christos Tsouris, ${ }^{b}$ David G. Billing, ${ }^{c}$ Andreas Lemmerer ${ }^{d}$ and Jonathan Charmant ${ }^{e}$ \\ Received 11th September 2010, Accepted 21st February 2011 \\ DOI: 10.1039/c0ce00634c
}

\begin{abstract}
The novel crystal structures of seven compounds which combine 2-phenylethylammonium cations and perhalometallate anions, all with the general formula $\left(\mathrm{C}_{8} \mathrm{H}_{9} \mathrm{NH}_{3}{ }^{+}\right)_{2} \mathrm{MX}_{4}{ }^{2-}$, were determined to establish the effect of metal atom and halogen ligand substitution on the structures and hydrogen bonding interactions. Five of the structures, bis(2-phenylethylammonium) tetrachlorozincate, $\left(\mathrm{C}_{8} \mathrm{H}_{9} \mathrm{NH}_{3}{ }^{+}\right)_{2} \mathrm{ZnCl}_{4}{ }^{2-}$, bis(2-phenylethylammonium) tetraiodozincate, $\left(\mathrm{C}_{8} \mathrm{H}_{9} \mathrm{NH}_{3}{ }^{+}\right)_{2} \mathrm{ZnI}_{4}{ }^{2-}$, bis $(2-$ phenylethylammonium) tetrabromodichloroiodozincate, $\left(\mathrm{C}_{8} \mathrm{H}_{9} \mathrm{NH}_{3}{ }^{+}\right)_{2} \mathrm{ZnCl}_{2} \mathrm{BrI}^{2-}$, bis $(2-$

phenylethylammonium) tetrabromocadmate, $\left(\mathrm{C}_{8} \mathrm{H}_{9} \mathrm{NH}_{3}{ }^{+}\right)_{2} \mathrm{CdBr}_{4}{ }^{2-}$, and bis(2-

phenylethylammonium) tetrabromomercurate, $\left(\mathrm{C}_{8} \mathrm{H}_{9} \mathrm{NH}_{3}{ }^{+}\right)_{2} \mathrm{HgBr}_{4}{ }^{2-}$, were found to be isostructural, while two of the compounds containing iodo ligands, bis(2-phenylethylammonium) tetraiodocadmate, $\left(\mathrm{C}_{8} \mathrm{H}_{9} \mathrm{NH}_{3}{ }^{+}\right)_{2} \mathrm{CdI}_{4}{ }^{2-}$, and bis(2-phenylethylammonium) tetraiodomercurate, $\left(\mathrm{C}_{8} \mathrm{H}_{9} \mathrm{NH}_{3}{ }^{+}\right)_{2} \mathrm{HgI}_{4}{ }^{2-}$, crystallize in a different, but related disordered structure. Strong $\mathrm{N}^{+}-\mathrm{H} \cdots \mathrm{X}^{-}-\mathrm{M}$ hydrogen bonding interactions, as well as weaker $\mathrm{C}-\mathrm{H} \cdots \pi$ aromatic interactions occur in all seven structures, and two robust tetrameric hydrogen bonded zero-dimensional motifs are present in all seven structures. $\mathrm{C}-\mathrm{H} \cdots$ $\mathrm{Cl}-\mathrm{M}$ hydrogen bonding interactions are present in the structure of bis(2-phenylethylammonium) tetrachlorozincate, and result in the distortion of the geometry of the 2-phenylethylammonium cation. Comparison of the identified zero-dimensional hydrogen bonding motifs with those occurring in related structures reported in the literature shows that the motifs are robust and can tolerate changes in cation, metal and ligand to a large extent.
\end{abstract}

\footnotetext{
${ }^{a}$ Department of Chemistry, University of Pretoria, Pretoria, 0002, South Africa. E-mail: melanie.rademeyer@up.ac.za; Fax: +27 12420 4687; Tel: +27124202511

${ }^{b}$ School of Chemistry, University of KwaZulu-Natal, Durban, 4041, South Africa.E-mail: ctsouris@gmail.com; Tel: +2711842 2076

'Molecular Science Institute, School of Chemistry, University of the Witwatersrand, Private Bag 3, PO Wits, 2050, South Africa. E-mail: dave.billing@wits.ac.za; Fax: +27 11717 6749; Tel: +27 117176759

${ }^{d}$ Molecular Science Institute, School of Chemistry, University of the Witwatersrand, Private Bag 3, PO Wits, 2050, South Africa. E-mail: andreas.lemmerer@wits.ac.za; Fax: +27 11717 6749; Tel: +27 11717 6711

${ }^{e}$ School of Chemistry, University of Bristol, Bristol, BS8 1TS, United Kingdom. E-mail: jon.charmant@bristol.ac.uk; Fax: +44 117929 0509; Tel: +441179288253

$\dagger$ Electronic supplementary information (ESI) available: Figure showing comparison of cation geometry, table of hydrogen bonding interactions involved in the formation of the zero-dimensional motifs in structures $1,2,3,4,5,8,9,10$ and 11, table of hydrogen bonding interactions and aromatic interactions involved in the formation of the one-, twoand three-dimensional motifs in structures $1,2,3,4,5,8,9,10$ and 11 , figures showing $\mathrm{M}-\mathrm{I} \cdots \mathrm{I}-\mathrm{M}$ close contacts in structures $\mathbf{6}$ and $\mathbf{9}$, and hydrogen bonded sheets in structures $\mathbf{1}$ and $\mathbf{9}$, figures showing zero-dimensional motifs in literature with square planar and tetrahedral anions. CCDC reference numbers 791566-791572. For ESI and crystallographic data in CIF or other electronic format see DOI: $10.1039 / \mathrm{c} 0 \mathrm{ce} 00634 \mathrm{c}$
}

\section{Introduction}

Organic-inorganic hybrid ionic materials provide the opportunity to join desired properties of both the organic and inorganic components when they self-assemble to give a composite crystal. ${ }^{1}$ The organic part may add structural diversity, while the inorganic constituent contributes properties like electrical conductivity, mechanical properties and magnetic behaviour. Perhalometallate anionic sheets may exert a templating effect on organic cations, ${ }^{2}$ and the organic cation component, in turn, affects the interlayer spacing, and may afford control over the type of inorganic sheet obtained.

Perhalometallate anions of $\mathrm{Cd}$ and $\mathrm{Hg}$ may exhibit a range of coordination polyhedra and dimensionalities ${ }^{3}$ while $\mathrm{Zn}$ perhalometallate anions typically adopt an isolated tetrahedral geometry.

Application of the templating effect of the cation on the inorganic component, and vice versa, requires a fundamental understanding of the interactions occurring between the components in the organic-inorganic hybrid, in order to control the structure and ultimately, the properties of the material. One branch of the field of crystal engineering aims to achieve this by employing supramolecular synthons to control the packing of units and the formation of periodic motifs. ${ }^{4}$ 
A number of studies have investigated the hydrogen bonding interactions and motifs in compounds containing simple arylammonium $\mathrm{N}^{+}-\mathrm{H}$ hydrogen bonding donors, and perhalometallate anion acceptors. Reported strategies include the variation of anion shape ${ }^{5}$ (square-planar, tetrahedral, octahedral, $1-d$ and 2-d polymeric) and variation of the cation ${ }^{6}$ (pyridinium, $4,4^{\prime}$-bipyridinium and related cations), which resulted in the identification of supramolecular synthons and hydrogen bonding donor positions. ${ }^{7}$ Relevant to the current investigation are studies which highlight the supramolecular synthons and motifs present in organic-inorganic hybrid compounds containing arylammonium cations with one hydrogen atom per donor atom and charge, and isolated tetrahedral tetrahalometallate anions.

The molecular cations previously reported include the 4,4'bipyridinium dication with tetrahedral anions $\mathrm{ZnCl}_{4}{ }^{2-}, \mathrm{ZnBr}_{4}{ }^{2-}$, $\mathrm{CoCl}_{4}{ }^{2-}, \mathrm{CoBr}_{4}{ }^{2-}$, and $\mathrm{HgCl}_{4}{ }^{2-}, 8$ the pyridinium cation with $\mathrm{CoCl}_{4}{ }^{2-}$ and $\mathrm{CuBr}_{4}{ }^{2-},{ }^{9}$ and the methyl-pyridinium cation with the $\mathrm{CuBr}_{4}{ }^{2-}$ anion. ${ }^{9}$ Structures consisting of isolated tetrahedral tetrahalometallate anions and pyridinium or methyl-pyridinium cations display motif A (Fig. 1), while structures containing 4,4'bipyridinium cations and isolated tetrahedral perhalometallate anions exhibit motif B (Fig. 1).

Absent from the reported studies are tetrahedral tetraiodometallate anions as well as arylammonium cations with increased hydrogen bonding capability.

The question can now be asked if motifs $\mathrm{A}$ and $\mathrm{B}$ will remain robust when the dimensionality of the hydrogen bonding network is increased by replacing the pyridinium nitrogen atom on the cation with an ammonium group and limiting the hydrogen bonding ability to one end of the molecule with potential aromatic interactions at the other end. The effect of the systematic variation of the halogeno and metal components in the perhalometallate anions on the motifs and crystal packing is also of interest.

In this investigation, the 2-phenylethylammonium cation was chosen as organic component of the hybrid compound because it contains three hydrogen atoms per charged nitrogen donor, and

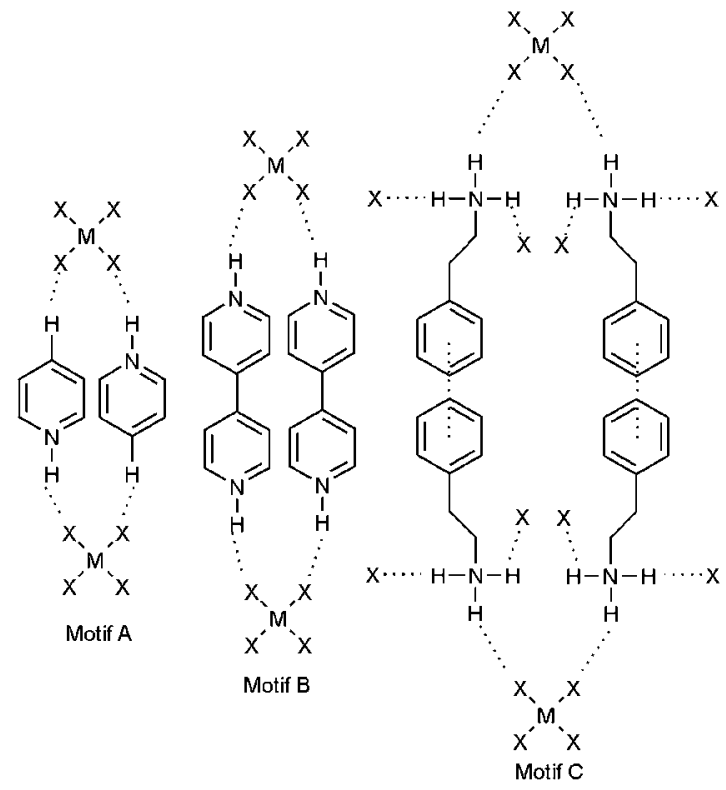

Fig. 1 Observed motifs A and B and predicted motif C. can thus potentially increase the dimensionality of the hydrogen bonding network. In addition, only one end of the molecule has hydrogen bonding capability, but the other end can potentially form aromatic interactions. Considering motifs $\mathrm{A}$ and $\mathrm{B}$, it was proposed that the replacement of the pyridinium or $4,4^{\prime}$-bipyridinium cations by 2-phenylethylammonium cations may result in the formation of motif $\mathrm{C}$ (Fig. 1) where aromatic interactions link cations, and the increased hydrogen bonding capability increases the dimensionality of the hydrogen bonding network.

The family of hybrid compounds containing the 2-phenylethylammonium cation and different perhalometallate anions, $\mathrm{M}_{q} \mathrm{X}_{r}{ }^{p-}(\mathrm{M}=\mathrm{Zn}, \mathrm{Cd}, \mathrm{Hg} ; \mathrm{X}=\mathrm{Cl}, \mathrm{Br}, \mathrm{I})$, was investigated structurally (see Scheme 1). In this paper structures will be referred to according to the abbreviation 2phenMX, where $\mathrm{M}$ indicates the metal atom and $\mathrm{X}$ the halide anion. For example, 2 phen $\mathrm{ZnCl}$ would indicate structure $\mathbf{1}$ in the matrix, namely bis(2-phenylethylammonium) tetrachlorozincate.

The structures of four members of the series have been reported in the literature. The compound $n\left(\mathrm{C}_{8} \mathrm{H}_{9} \mathrm{NH}_{3}{ }^{+}\right)$ $\left(\mathrm{CdCl}_{4}{ }^{2-}\right)_{n}, 4,{ }^{10}$ which contains 2-phenylethylammonium cations and $\mathrm{CdCl}_{4}{ }^{2-}$ units, is of the layered perovskite type. In the current study, the combination of 2-phenylethylammonium chloride and $\mathrm{CdCl}_{2}$ in a 2:1 molar ratio yielded the same perovskite compound. The compound $n\left(\mathrm{C}_{8} \mathrm{H}_{9} \mathrm{NH}_{3}{ }^{+}\right)\left(\mathrm{HgCl}_{3}\right)_{n}$, $7,{ }^{11}$ was reported for the combination of 2-phenylethylammonium chloride and $\mathrm{HgCl}_{2}$. In this structure $\mathrm{HgCl}_{3}{ }^{-1}$ units combine to form an infinite, one-dimensional perhalometallate chain. The structures of the tetrabromozincate member of the family, $\left(\mathrm{C}_{8} \mathrm{H}_{9} \mathrm{NH}_{3}{ }^{+}\right)_{2} \mathrm{ZnBr}_{4}{ }^{2-}, \mathbf{2},{ }^{12}$ and the mixed-metal compound $\left(\mathrm{C}_{8} \mathrm{H}_{9} \mathrm{NH}_{3}{ }^{+}\right)_{2} \mathrm{Cd}_{0.75} \mathrm{Hg}_{0.25} \mathrm{Br}_{4}{ }^{2-}, \mathbf{1 1},{ }^{13}$ in which a quarter of the metal positions are occupied by $\mathrm{Hg}$, and the rest by $\mathrm{Cd}$, are isostructural to other members in the series, and will be included in the current comparison.

The aim of the current study is to structurally investigate the outstanding members of the series in order to highlight the effect of variation of the divalent metal and halogeno ligands on packing trends and supramolecular motifs, and to compare the motifs present to those in related structures in the literature.

\section{Results}

The asymmetric unit of all seven novel structures 2 phen $\mathrm{ZnCl}, \mathbf{1}$, 2phenZnI, 3, 2phenCdBr, 5, 2phenCdI, 6, 2phenHgBr, 8, 2phenHgI, 9 and 2 phen $\mathrm{ZnCl}_{2} \mathrm{BrI}, \mathbf{1 0}$, comprise two crystallographically inequivalent 2-phenylethylammonium cations and one isolated tetrahedral tetrahalometallate anion. The asymmetric units and atomic numbering scheme are illustrated in Fig. 2, and selected crystallographic parameters listed in Table 1.

In the seven novel structures and the structures 2 phen $\mathrm{ZnBr}, \mathbf{2}^{\mathbf{1 2}}$ and 2 phen $\mathrm{Cd} / \mathrm{HgBr}, \mathbf{1 1}^{13}$ reported in the literature, the 2-phenylethylammonium molecular cation and tetrahedral tetrahalometallate anion combine in a 2:1 ratio to form compounds of the formula $\left(\mathrm{C}_{8} \mathrm{H}_{9} \mathrm{NH}_{3}{ }^{+}\right)_{2} \mathrm{MX}_{4}{ }^{2-}$. Although all the compounds have the same general formula, two types of structures are observed. Compounds 2phenZnCl, 1, 2phenZnBr 2, ${ }^{\mathbf{1 2}}$ 2phenZnI, 3, 2phenCdBr, 5, 2phenHgBr, 8, 2phenZnCl ${ }_{2} \mathrm{BrI}, 10$ and 2 phenCd/ $\mathrm{HgBr}, \mathbf{1 1}^{13}$ all crystallize in space group $P 2_{1} / c$ with similar unit cell dimensions, and are isostructural. The type of structure exhibited by these compounds will be called structure type I. Compounds 


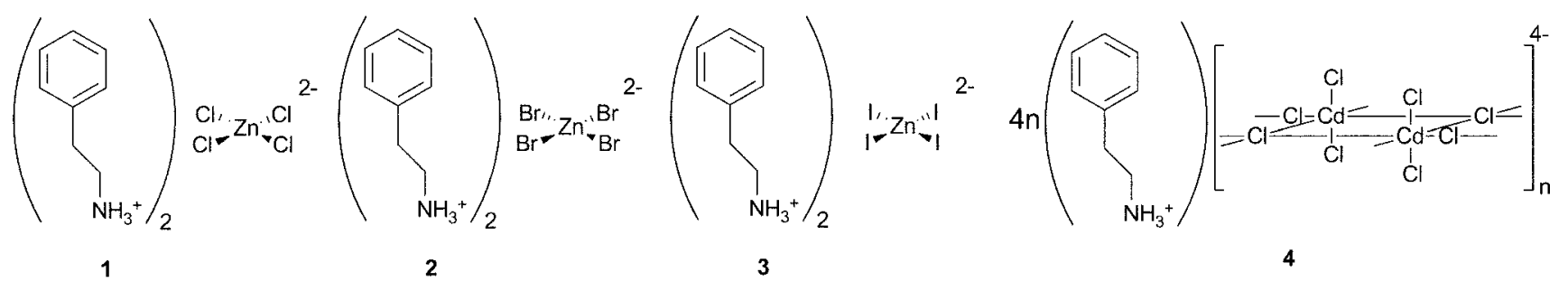

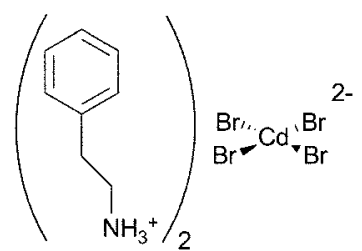

5

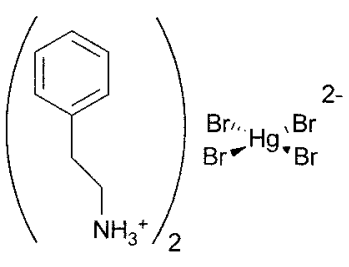

8

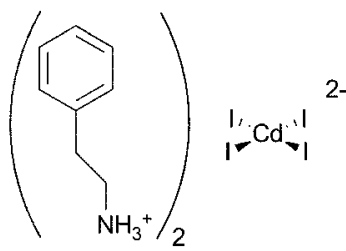

6

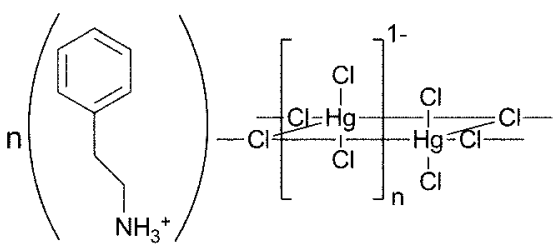

7

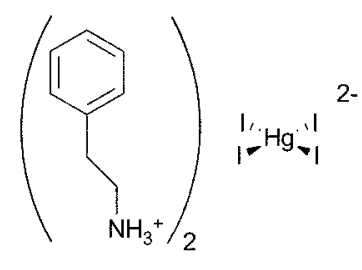

9

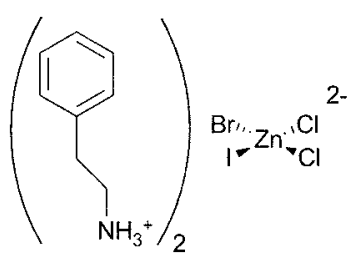

10

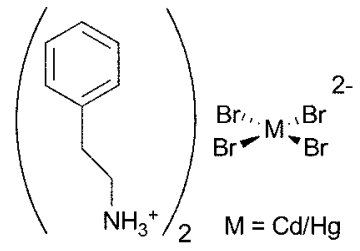

11

Scheme 1 Compounds in the bis(2-phenylethylammonium) tetrahalometallate series.

2phenCdI, 6, and 2phenHgI, 9, are isostructural and form structure type II, crystallizing in the chiral space group $P 2_{1}$. The absolute structures could not be determined, and in both these structures one of the two cations is disordered over two positions (occupancies of $0.15: 0.85$ for structure 2phenCdI, 6, and $0.12: 0.88$ for structure 2 phenHgI, 9 respectively). Literature structures 2 phenCdCl, $4,{ }^{10}$ and 2 phen $\mathrm{HgCl}, 7,{ }^{11}$ show chemical formulae differing from the rest of the structures due to the formation of polymeric anions, and will not be included in the current comparison. In structure types I and II two unit cell parameters are similar, while the third is approximately double in structure type I compared to structure type II. As a result the unit cell volume of structure type I is roughly twice that of structure type II, with $Z=4$ and 2 respectively.

\section{Degree of isostructurality}

The unit cell parameters of the isostructural compounds were compared using the unit cell similarity index, $\pi$, defined by Fábián and Kálmán, ${ }^{14}$ the mean elongation, $\varepsilon$, and the asphericity index, $A$, both defined by Rutherford. ${ }^{15}$ The volumetric isostructurality index, $I_{\mathrm{v}},{ }^{14}$ was employed to determine the similarity between novel structures based on the fractional coordinates of the atoms in the unit cell. The values of these respective parameters for the comparison of pairs of structures are listed in Table 2. The smaller the values of $\pi$ and $\varepsilon$, and the larger the value of $A$, the more similar the unit cell dimensions, and the higher $I_{\mathrm{v}}$ the higher the agreement between fractional coordinates.

The values in Table 2 reveal that the structures 2 phen $\mathrm{ZnCl}, \mathbf{1}$, and 2 phen $\mathrm{ZnBr}, 2$, are relatively similar in terms of unit cell and atomic positions in the cell, but that the structure of the third member of the tetrahalozincate series, 2 phenZnI, 3, differs from structure 1 to a relatively large extent. This difference is evident from the distinctly low $I_{\mathrm{v}}$ value of $62.3 \%$, and highest overall values for $\pi$ and $\varepsilon$, which means that the change in the ligands from bromo to iodo in the tetrahalozincate series has a relatively large effect on the crystal structure, but does not cause a changeover to structure type II.

All the tetrabromometallate salts (2phen $\mathrm{ZnBr}, 2,2$ phenCdBr, 5, 2 phen $\mathrm{HgBr}, 8$, and 2 phen $\mathrm{Cd} / \mathrm{HgBr}$ 11) exhibit similar unit cell dimensions and fractional coordinates, with $I_{\mathrm{v}}$ exceeding $90 \%$ in each of the comparisons. This indicates that a systematic change in $\mathrm{d}^{10}$ divalent metal atom does not significantly change the crystal structure in this series. In addition, the unit cell parameters and fractional coordinates of the mixed ligand compound 2 phen $\mathrm{ZnCl}_{2} \mathrm{BrI}, \mathbf{1 0}$, are also in high agreement with those of the structures in the tetrabromometallate series.

The unit cell parameters and fractional coordinates of structures 2 phenCdI, 6, and 2phenHgI, 9, where the metal atom changes from $\mathrm{Cd}$ to $\mathrm{Hg}$, but the iodo ligands remain constant, are alike. However in the iodo-ligand series the change from $\mathrm{Zn}$ to $\mathrm{Cd}$ results in a cross-over from structure type I to structure type II. Thus, the effect of an increase in metal atom size is more pronounced in the case of the larger iodo-ligand containing structures, compared to the bromo-ligand structures. It appears that with an increase in both ligand and metal size (i.e. $\mathrm{Cd}$ or $\mathrm{Hg}$ combined with iodo ligands), a point is reached where the relative size of the anion is large enough to induce a change from structure type I to structure type II.

\section{Crystallographic discussion of structures}

All the compounds exhibit a layered structure consisting of alternating organic and inorganic layers. The inorganic layer 


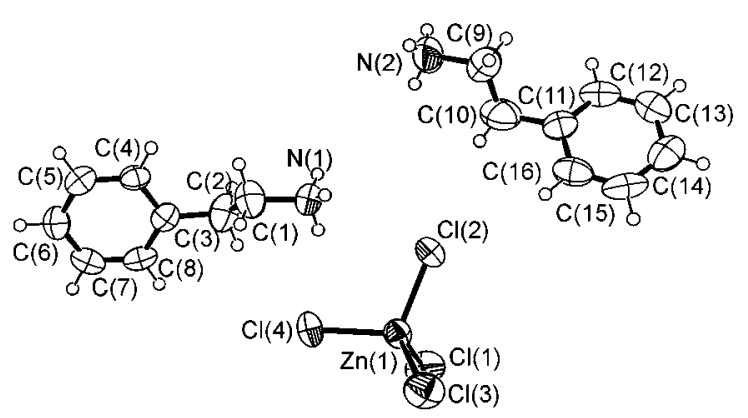

1
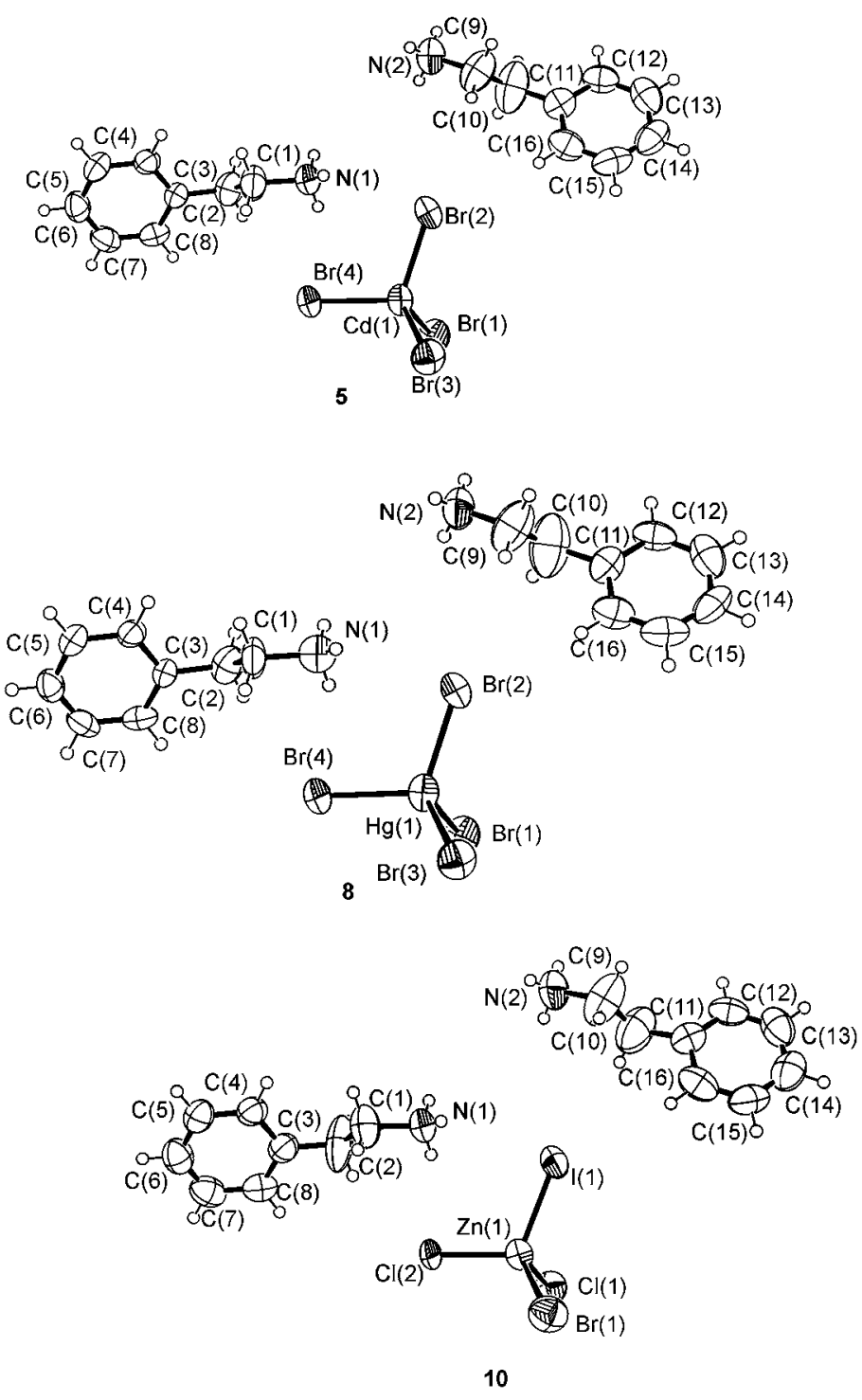
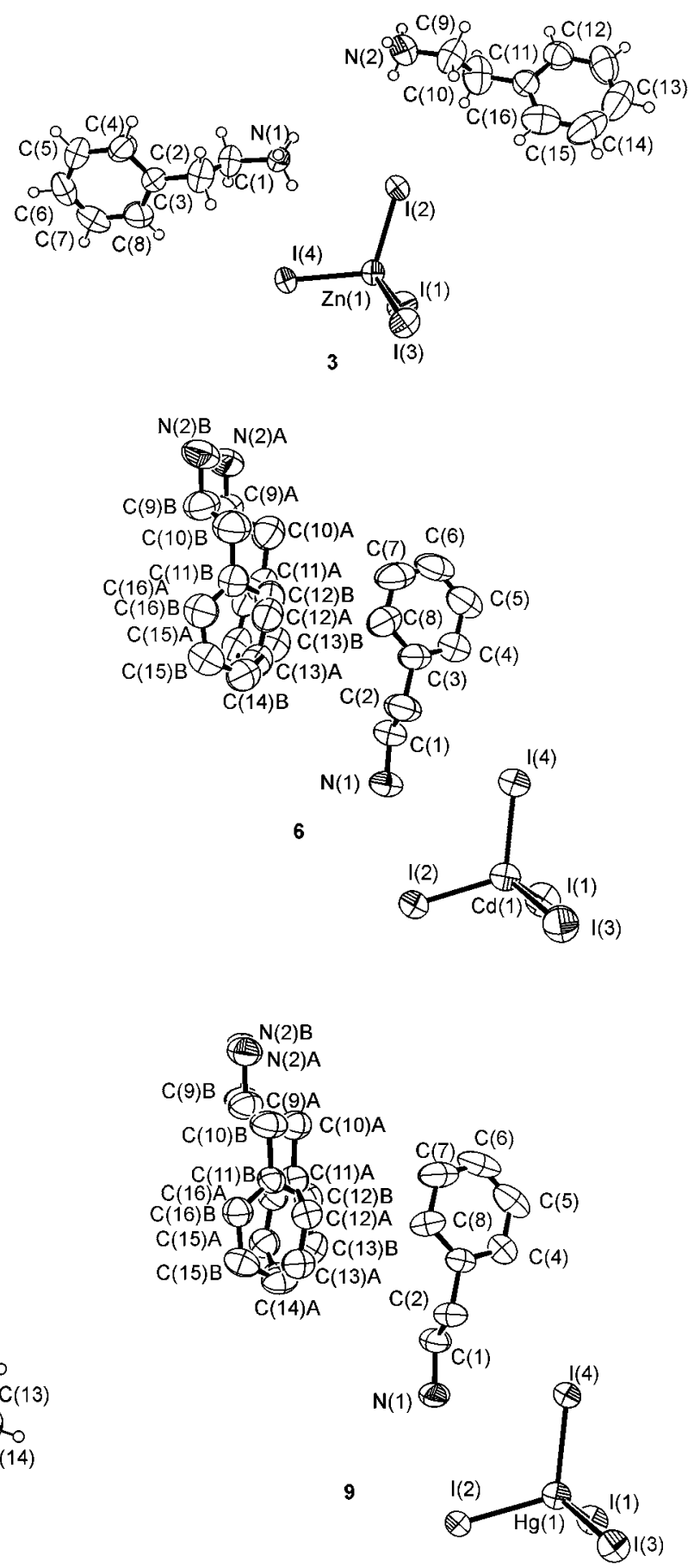

Fig. 2 Asymmetric units of novel structures 1, 3, 5, 6, 8,9 and 10, illustrating the atomic numbering scheme. Ellipsoids are drawn at the $50 \%$ probability level. Hydrogen atoms are omitted in structures $\mathbf{6}$ and $\mathbf{9}$ for clarity.

contains discrete tetrahedral tetrahalometallate anions and ammonium groups, all interacting via hydrogen bonding. In the organic layer the 2-phenylethyl moieties pack with their aromatic groups in a single layer, interacting through aromatic interactions.

\section{Comparison of structure types I and II}

Even though structure types I and II are not isostructural, they are alike structurally. The molecular packing in structure $2 \mathrm{phenCdBr}$, 5 (representative of structure type I), and structure 2phenCdI, 6 


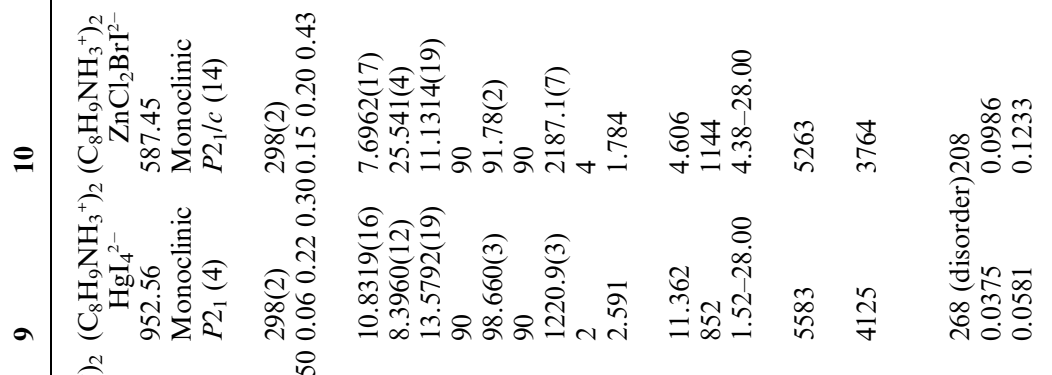

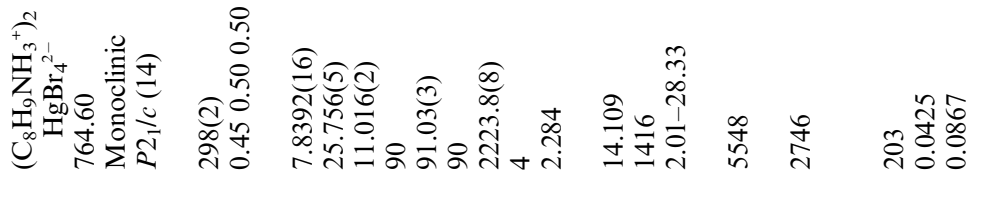

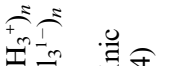

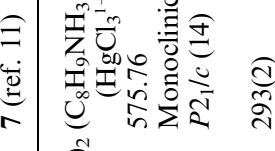

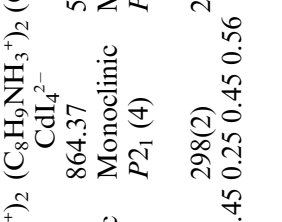
(1) त

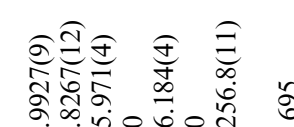

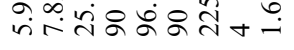
ถูำ

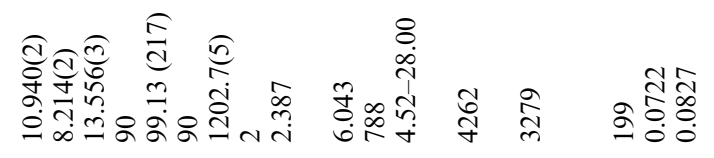

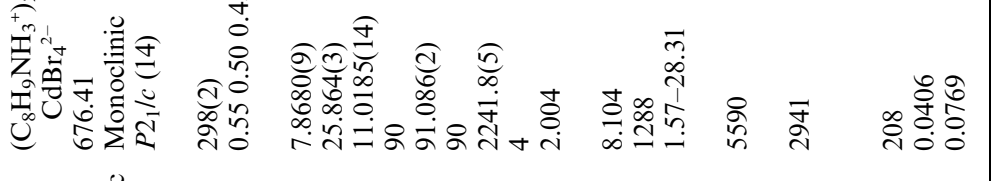

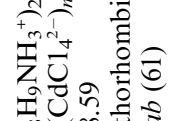

总 व के कू

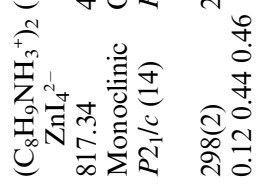

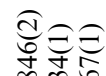

min 
Table 2 Isostructurality parameters

\begin{tabular}{lrllll}
\hline \multicolumn{2}{l}{ Structures } & \multicolumn{1}{l}{$\boldsymbol{\pi}$} & $A$ & $I_{\mathrm{v}}(\%)$ \\
\hline $\mathbf{1}$ & $\mathbf{2}$ & 0.02496 & 0.0218053 & 0.345205 & 84.1 \\
$\mathbf{1}$ & $\mathbf{3}$ & 0.06368 & 0.0574127 & 0.423091 & 62.3 \\
$\mathbf{1}$ & $\mathbf{5}$ & 0.03422 & 0.0309805 & 0.469094 & 79.4 \\
$\mathbf{1}$ & $\mathbf{8}$ & 0.03099 & 0.0282063 & 0.490604 & 79.9 \\
$\mathbf{1}$ & $\mathbf{1 0}$ & 0.02538 & 0.0225192 & 0.362273 & 83.4 \\
$\mathbf{1}$ & $\mathbf{1 1}$ & 0.03724 & 0.0339635 & 0.420573 & 78.6 \\
$\mathbf{2}$ & $\mathbf{3}$ & 0.03777 & 0.0348475 & 0.494410 & 71.7 \\
$\mathbf{2}$ & $\mathbf{5}$ & 0.00903 & 0.0089794 & 0.822938 & 91.7 \\
$\mathbf{2}$ & $\mathbf{8}$ & 0.00588 & 0.0062644 & 1.078240 & 92.0 \\
$\mathbf{2}$ & $\mathbf{1 0}$ & 0.00040 & 0.0006986 & 2.997170 & 92.1 \\
$\mathbf{2}$ & $\mathbf{1 1}$ & 0.01198 & 0.0118987 & 0.598945 & 90.9 \\
$\mathbf{3}$ & $\mathbf{5}$ & 0.02848 & 0.0256379 & 0.394823 & 76.4 \\
$\mathbf{3}$ & $\mathbf{8}$ & 0.03169 & 0.0284052 & 0.378835 & 75.9 \\
$\mathbf{3}$ & $\mathbf{1 0}$ & 0.03735 & 0.0341251 & 0.500021 & 72.3 \\
$\mathbf{3}$ & $\mathbf{1 1}$ & 0.02548 & 0.0226790 & 0.455958 & 77.1 \\
$\mathbf{5}$ & $\mathbf{8}$ & 0.00312 & 0.0026981 & 0.321541 & 97.8 \\
$\mathbf{5}$ & $\mathbf{1 0}$ & 0.00862 & 0.0082750 & 0.860098 & 90.0 \\
$\mathbf{5}$ & $\mathbf{1 1}$ & 0.00292 & 0.0028933 & 0.105718 & 98.2 \\
$\mathbf{8}$ & $\mathbf{1 0}$ & 0.00547 & 0.0055618 & 1.190740 & 90.2 \\
$\mathbf{8}$ & $\mathbf{1 1}$ & 0.00606 & 0.0055992 & 0.112269 & 98.9 \\
$\mathbf{1 0}$ & $\mathbf{1 1}$ & 0.01157 & 0.0111923 & 0.617381 & 89.4 \\
$\mathbf{6}$ & $\mathbf{9}$ & 0.00322 & 0.0050147 & 1.292700 & 96.1 \\
\hline
\end{tabular}

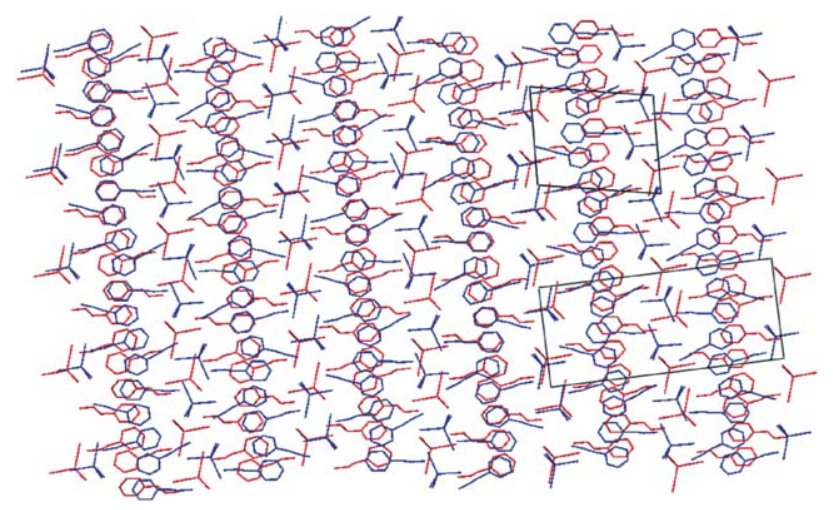

Fig. 3 Overlay of structures 2 phenCdBr, 5 (blue, viewed down $a$-axis), and 2phenCdI, 6 (red, viewed down $b$-axis), to illustrate the structural similarity. Only the cation with the highest occupancy is shown for structure 6. Unit cell outlines are showed for structure type I (bottom right corner), and structure type II (top right corner).

(representative of structure type II), is compared in Fig. 3. In this figure the tetrahalometallate anions of the third inorganic layer from the right as well as the far left inorganic layer are approximately superimposed, employing the programme Mercury 2.2. ${ }^{16}$ The orientation of the cations in the two organic layers neighbouring the superimposed inorganic layer is the same for structure types I and II, but in the next two organic layers, cations point in opposite directions in the two structures. Thus, pairs of organic layers in which the cation orientation is the same alternate with pairs of organic layers displaying different cation orientations in the two structures. In the three inorganic layers to the left of the superimposed inorganic layer, the anions are not superimposed, but in every fifth inorganic layer the structures display the same anion orientation and approximate position.

Structure types I and II may be considered to be polytypes. These are structures that are obtained by the stacking of the same layers, but differing in the stacking sequence of individual layers.

\section{Cation geometry}

The molecular geometries of the two crystallographically independent cations in all the structures were compared. The cations containing atom $\mathrm{N}(1)$ will be referred to as cation 1 , and the cations containing atom $\mathrm{N}(2)$, cation 2 . In the ideal conformation of the 2-phenylethylammonium cation in the gas phase the $\mathrm{N}-\mathrm{C}-\mathrm{C}-\mathrm{C}$ ethylammonium chain is in the trans conformation, and the plane through this chain is perpendicular to the aromatic ring plane, with atom $\mathrm{C}(2)$ in cation 1 (and $\mathrm{C}(10)$ in cation 2) axial to the aromatic plane, and with a mirror plane passing through the ethylammonium chain, perpendicular to the aromatic ring. ${ }^{17}$

Any distortion from the ideal geometry may be quantified using three parameters. ${ }^{17}$ The $\mathrm{N}-\mathrm{C}-\mathrm{C}-\mathrm{C}$ torsion angle, $\varphi$, is a measure of the distortion of the ethylammonium chain from the all-trans conformation. The angle between the aromatic plane and alkyl carbon zigzag plane, $\theta$, indicates the tilt of the chain relative to the aromatic plane, with an ideal value of $90^{\circ}$. The third parameter, $\sigma$, refers to the magnitude of the deviation of atom $C(1)$ (and $C(9)$ ) from the aromatic plane, and indicates the distortion of the ethylammonium chain in a direction above or below the aromatic plane.

The parameters describing the cation geometries are listed in Table 3. The ethylammonium chains all adopt approximately all-trans geometries since the $\varphi$ angles do not deviate significantly from $180^{\circ}$ for any of the cations, with structures 2phenCdI, 6, and 2phenHgI, 9 (both structure type II), exhibiting the largest deviation from the ideal $\varphi$ value in both cation 1 and cation 2 .

Comparison of the geometries of all the cations containing atom $\mathrm{N} 1$ reveals that the torsion angle $\theta$ is similar for all the tetrabromometallate salts 2 phenZnBr, 2, 2phenCdBr, 5, 2 phen $\mathrm{HgBr}, 8$ and 2 phen $\mathrm{Cd} / \mathrm{HgBr}, \mathbf{1 1}^{13}$ (values between $53.8^{\circ}$ and $\left.55.5(7)^{\circ}\right)$. In the same way $\theta$ values for the tetraiodometallate salts 2 phenZnI, 3, 2phenCdI, 6, and 2phenHgI, 9, are similar (values range from $71(1)^{\circ}$ to $\left.75.0(9)^{\circ}\right)$, despite the fact that structure 2phenZnI, 3, is a type I structure, and 2phenCdI, 6, and 2phenHgI, 9, exhibit structure type II. Cation 1 in structures 2 phen $\mathrm{ZnCl}, \mathbf{1}$, and 2 phen $\mathrm{ZnCl}_{2} \mathrm{BrI}, \mathbf{1 0}$, exhibits larger deviations from the ideal geometry than the rest, with $\theta$ values of $48.2(6)^{\circ}$ and $42(2)^{\circ}$ respectively. The largest deviation of atom $\mathrm{C}(1)$ from the aromatic plane $(\sigma)$ is observed for structures 2 phenCdI, 6, and 2phenHgI, 9, of structure type II, with values of approximately $1.2 \AA$ and $1.3 \AA$ respectively.

In the structures 2 phenZnBr, 2, 2phenZnI, 3, 2phenCdI, 6, 2 phenHgI, 9, and $2 \mathrm{phenZnCl}_{2} \mathrm{BrI}, \mathbf{1 0}$, cations containing atom $\mathrm{N} 2$ adopt similar geometries, with $\theta$ values ranging from $75(1)^{\circ}$ to $89(2)^{\circ}$. Structures 2 phenCdBr, 5, 2phenHgBr, 8, and 2 phen $\mathrm{Cd} / \mathrm{HgBr}, 11$ (all bromo-ligand containing), exhibit $\theta$ angles in the range $64.7(8)^{\circ}$ to $67(1)^{\circ}$. The $\sigma$ values for cation 2 indicate that the iodo-ligand containing structures 3, 6 and 9 show the largest deviation of atom $\mathrm{C}(9)$ from the aromatic plane. An obvious exception for the geometry of cation 2 is observed in structure 2 phen $\mathrm{ZnCl}, \mathbf{1}$, in which the ethylammonium chain is tilted by $54.2(5)^{\circ}$ relative to the aromatic plane, indicating a much larger deviation from ideal geometry than observed for any of the other structures. 
Table 3 Parameters describing cation geometry

\begin{tabular}{|c|c|c|c|c|c|c|c|}
\hline Structure & Structure type & \multicolumn{3}{|l|}{ Cation 1} & \multicolumn{3}{|l|}{ Cation 2} \\
\hline 2 & I & 178.6 & 53.8 & 0.857 & 176.9 & 83.0 & 1.014 \\
\hline 3 & I & $175.7(10)$ & $73(1)$ & $0.895(16)$ & $177.2(11)$ & $75(1)$ & $1.098(12)$ \\
\hline 5 & I & $176.5(6)$ & $55.2(5)$ & $1.021(7)$ & $179.4(7)$ & $64.7(8)$ & $0.905(8)$ \\
\hline 6 & II & $172.0(15)$ & 71(1) & $1.167(17)$ & $174(2)$ & $89(2)$ & $1.11(2)$ \\
\hline 10 & I & $177.8(15)$ & $42(2)$ & $0.739(15)$ & $177.2(18)$ & $83(2)$ & $0.84(2)$ \\
\hline 11 & I & 176.1 & 54.4 & 1.015 & 179.5 & 65.3 & 0.881 \\
\hline
\end{tabular}

\section{Hydrogen bonding and aromatic interactions}

The deconstruction of the structures into smaller motifs and an analysis of the hydrogen bonding and aromatic interactions were performed to assist in the identification of robust supramolecular motifs, and to explain the atypical geometry observed for cation 2 in the structure 2 phen $\mathrm{ZnCl}, \mathbf{1}$. Only the cations with the highest occupancy were considered in the analysis of the hydrogen bonding and aromatic interactions of structures 2 phenCdI, 6 , and 2phenHgI, 9.

\section{Zero-dimensional motifs}

One way of describing the structures is to consider hydrogen bonded tetramers as zero-dimensional motifs. Each tetramer consists of two tetrahalometallate anions and two cations. The two crystallographically independent cations do not occur in the same tetramer. All motifs were oriented such that the halogeno ligands of the tetrahalometallate anions placed in the top and bottom positions adopt the same unique spacial orientation (top and bottom ligands in top anion point out of the page). In structure type I, the tetramers are centrosymmetric, but this is not the case for structure type II. Two types of zero-dimensional motifs are present in each structure, one for each cation, and they differ in the type and number of hydrogen bonding interactions involved in the formation of the motif. The two types will be referred to as motif 1 , involving cation 1 (containing atom $\mathrm{N}(1)$ ), and motif 2 , involving cation 2 . Hydrogen bonding interactions involved in the formation of zero-dimensional motifs are listed in Table $\mathrm{S} 1 \dagger$.

Schematic and more generic representations of the tetramer motifs 1 and 2 found for structure types I and II are shown in Fig. 4a and b. Weak C-H $\cdots \mathrm{X}-\mathrm{M}$ hydrogen bonding interactions are omitted for clarity. Motifs 1 and 2 are similar, and differ only in the number of anion halogeno ligands that act as hydrogen bonding acceptors, with two ligands accepting hydrogen bonds in motif 1 , but only one ligand accepting hydrogen bonds in motif 2 .

Zero-dimensional motif 1 . The same motif 1 is observed in structures 2phen $\mathrm{ZnCl}, \mathbf{1}$, 2phen $\mathrm{ZnBr}, \quad \mathbf{2}$, 2phenCdBr, 5, 2phenCdI, 6, 2phenHgBr, 8, 2phenHgI, 9 and 2 phenCd/HgBr, 11, but structures 2 phenZnI, 3 and 2 phen $\mathrm{ZnCl}_{2} \mathrm{BrI}, 10$ display additional hydrogen bonding interactions in their motif 1 's, compared to the rest, as illustrated in Fig. 5. In the general motif 1 two hydrogen atoms on each ammonium group hydrogen bond

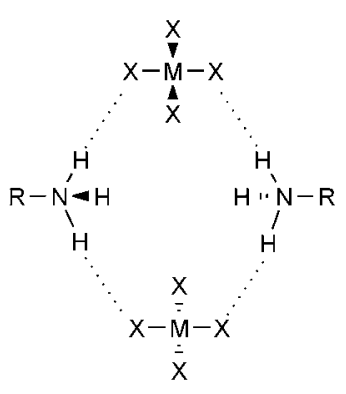

(a)

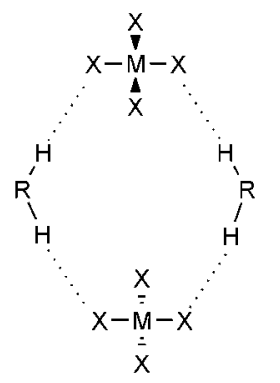

(c)

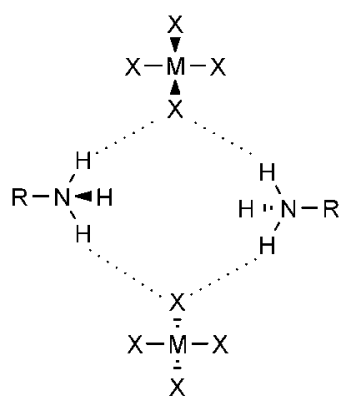

(b)

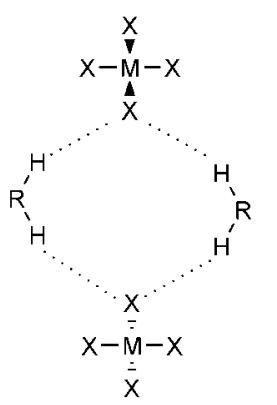

(d)
Fig. 4 (a) Schematic representation of motif 1, (b) motif 2, (c) generic motif 1 and (d) generic motif 2 .
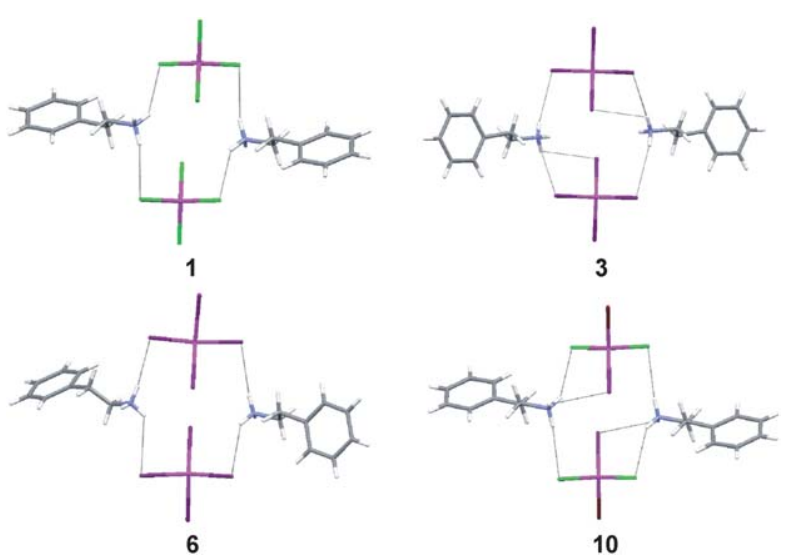

Fig. 5 Centrosymmetric motif 1 in structure 1 (also observed for structures $2, \mathbf{5}, \mathbf{8}$ and 11), centrosymmetric motif in structure 3 , noncentrosymmetric motif 1 in structure $\mathbf{6}$ (also observed for structure 9), and centrosymmetric motif in structure $\mathbf{1 0 .}$ 
to two halogeno ligands on different $\mathrm{MX}_{4}{ }^{2-}$ tetrahedra. Each tetrahedral anion accepts two hydrogen bonds, one from each cation, with two different ligands acting as acceptors. The graph set notation $R_{4}{ }^{4}(12)$ describes this ring-motif. Motif 1 in structure 3, 2phenZnI, displays an additional hydrogen bond to a second iodo ligand (Fig. 5). In the structure 2 phen $\mathrm{ZnCl}_{2} \mathrm{BrI}, \mathbf{1 0}$, the electronegative chloro ligands are involved in the formation of the general motif 1 described above, resulting in the strongest possible hydrogen bonds.

Zero-dimensional motif 2 . The zero-dimensional motifs involving cation 2 are illustrated in Fig. 6. The general motif 2, as observed in structures 2 phen $\mathrm{HgBr}, \mathbf{8}, 2$ phen $\mathrm{ZnCl}_{2} \mathrm{BrI}, \mathbf{1 0}$, and $2 \mathrm{phenCd} / \mathrm{HgBr}, \mathbf{1 1}$, is a centrosymmetric tetramer formed by four hydrogen bonding interactions. Two hydrogen atoms on each ammonium group hydrogen bond to two different anions, forming a hydrogen bonded ring in the centre of the motif, described by graph set notation $R_{4}^{2}(8)$. Contrary to what is observed in motif 1 , only one halogeno-ligand on each anion acts as hydrogen bond acceptor. In the case of the mixed ligand structure 2 phen $\mathrm{ZnCl}_{2} \mathrm{BrI}, \mathbf{1 0}$, the two chloro ligands are the hydrogen bond acceptors. Motif 2 in structures 2 phen $\mathrm{ZnCl}, \mathbf{1}$, and 2 phenCdBr, 5, display the interactions in the general motif 2 , but also include an additional weak $\mathrm{C}(10)-\mathrm{H}(10 \mathrm{~B}) \cdots \mathrm{Cl}(4)$ interaction in 1 , and a weak $\mathrm{C}(10)-\mathrm{H}(10 \mathrm{~A}) \cdots \mathrm{Br}(4)$ interaction in
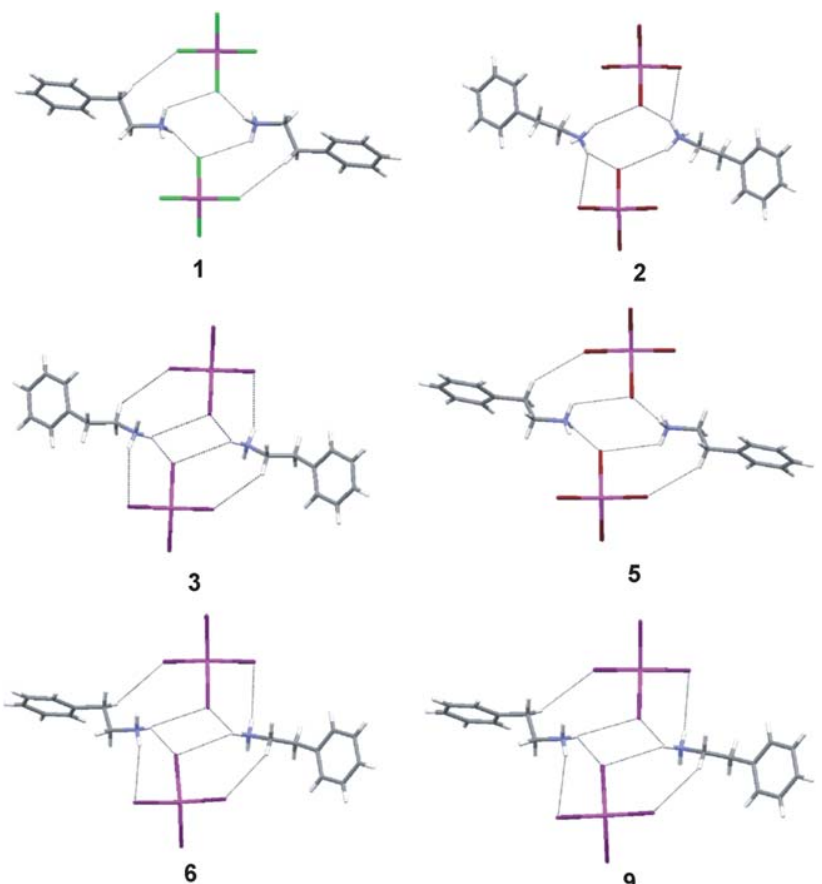

5
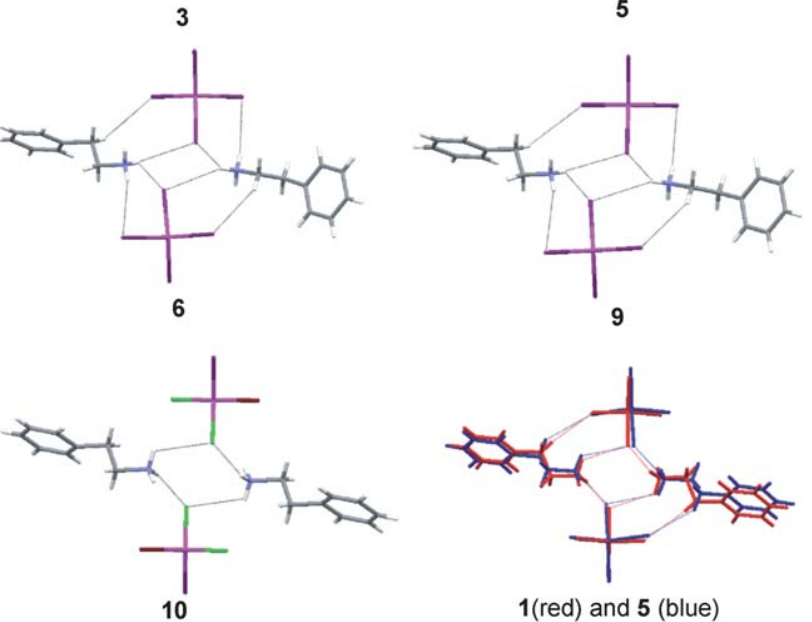

Fig. 6 Motif 2 in structures 1, 2, 3, 5, 6, 9 and 10 (also observed in structures $\mathbf{8}$ and 11), and superposition of motif 2 of structures $\mathbf{1}$ and $\mathbf{5}$.
2 phenCdBr, 5. Different hydrogen atoms are involved in this weak interaction in the two structures as can be seen from a superposition of the two motifs in Fig. 6. This illustrates how the flexible nature of the ethylammonium moiety allows for the distortion of the cation geometry in order to allow for the formation of weaker hydrogen bonds. The distortion of the geometry of cation 2 in structure 1 noted previously, as expressed in terms of $\theta$, may be explained by this additional hydrogen bonding from the $\mathrm{C}-\mathrm{H}$ donor to the chloro ligand, which is a good hydrogen bond acceptor. The decrease in stabilization due to the higher energy conformation of the cation is expected to be off-set by the increase in stabilization caused by the additional weak hydrogen bonding interactions.

Because the hydrogen bonding interaction to the bromo ligand in 2 phenCdBr, 5 is weaker, and it involves a different hydrogen atom, it does not distort the cation geometry significantly from the ideal geometry. Motif 2 in structures 2 phen $\mathrm{ZnBr}$ and 2phenZnI (structures $\mathbf{2}$ and $\mathbf{3}$ respectively) also displays the interactions observed in the general motif 2 , as well as an additional interaction involving one of the hydrogen atoms on the ammonium group already involved in hydrogen bonding.

In structures 2 phenCdI, 6, and 2phenHgI, 9, only one hydrogen atom on each ammonium group is involved in the formation of the central hydrogen bonded ring involving one ligand acceptor on two different anions (see Fig. 6), and a second hydrogen atom on each ammonium group hydrogen bonds to a second ligand on each anion. A weak $\mathrm{C}(9)-\mathrm{H} \cdots \mathrm{I}$ interaction and a weak $\mathrm{C}(10)-\mathrm{H} \cdots \mathrm{I}$ interaction are present. These interactions result in the deviation of the cation geometry from the ideal geometry, indicated by the isostructurality parameters.

One-dimensional motifs. Neighbouring zero-dimensional motifs interact via weak, T-shaped $\mathrm{C}-\mathrm{H} \cdots \pi$ interactions to form one-dimensional columns, as illustrated in Fig. 7 and listed in Table S $2 \uparrow$. In the case of structure type I, motifs 1 and 2 alternate in the one-dimensional column parallel to the $c$-axis (Fig. 7a). However, for structure type II, each one-dimensional chain contains only one motif, with alternating one-dimensional chains extending along the $c$-axis (Fig. 7b).

Two-dimensional motifs. In all the structures, neighbouring one-dimensional columns share $\mathrm{MX}_{4}{ }^{2-}$ anions to form a twodimensional sheet (Fig. 8a and b). In addition weak $\mathrm{C}-\mathrm{H} \cdots \pi$

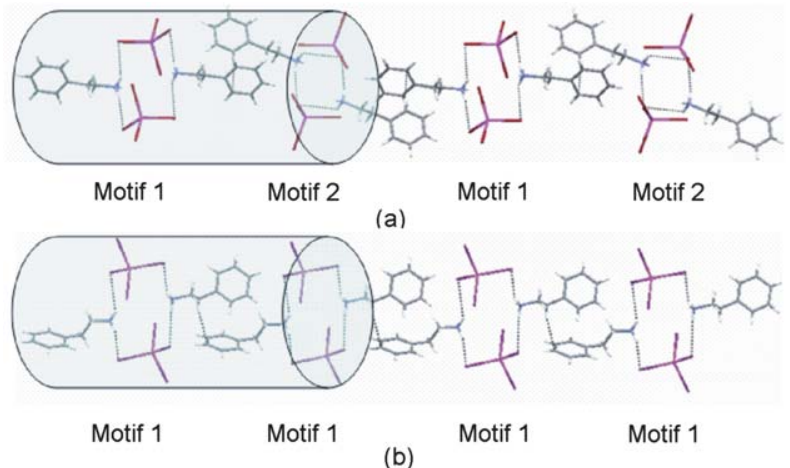

Fig. 7 One dimensional motifs showing aromatic interactions in (a) structure type I and (b) structure type II. 


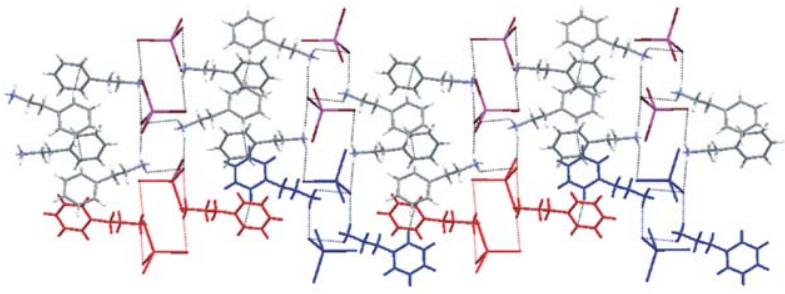

(a)

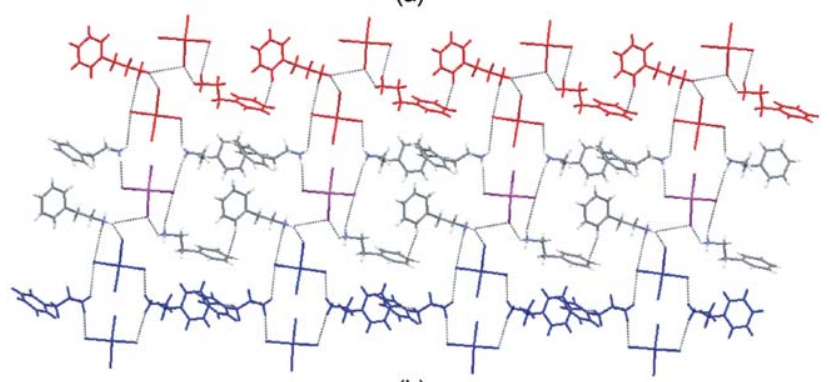

(b)

Fig. 8 Two-dimensional sheet motifs in (a) structure type I (motif 1 in blue and motif 2 in red alternating in bottom row) and (b) structure type II (motif 1 in blue in bottom row and motif 2 in red in top row).

interactions also link neighbouring one-dimensional columns, as listed in Table $\mathrm{S} 2 \uparrow$. The combination of all the hydrogen bonding interactions results in a two-dimensional hydrogen bonded sheet network, parallel to the $a c$-plane in structure type I, and parallel to the $a b$-plane in structure type II.

Three-dimensional motifs and hydrogen bonding network. Neighbouring two-dimensional sheets are linked via strong $\mathrm{N}^{+}$ $\mathrm{H} \cdot{ }^{-} \mathrm{X}-\mathrm{M}$ hydrogen bonding interactions in all the structures, with intra-sheet interactions listed in Table $\mathrm{S} 2 \uparrow$. In structure type II, intra-sheet $\mathrm{M}-\mathrm{I} \cdots \mathrm{I}-\mathrm{M}$ close contacts are present (Fig. S2 $\dagger$ ). Here two iodo ligands per anion are in close contact with iodo ligands on neigbouring anions, with an I $\cdots$ I distance of 3.864(2) $\AA$ and 3.9211(8) A for structures 2phenCdI, 6, and 2phenHgI, 9, respectively. A linear, one-dimensional motif of the type I-M$\mathrm{I} \cdots \mathrm{I}-\mathrm{M}-\mathrm{I} \cdots \mathrm{I}-\mathrm{M}-\mathrm{I}$ results.

Halogen-halogen interactions of the type $\mathrm{C}-\mathrm{X} \cdots \mathrm{X}-\mathrm{A}$, where $\mathrm{A}$ may be a metal or $\mathrm{C}$ atom and $\mathrm{C}-\mathrm{X}$ acts as a Lewis acid and $\mathrm{X}$ $\mathrm{A}$ as a Lewis base, have been reported and discussed in numerous studies in the literature. ${ }^{18}$ However, the interaction between two Lewis bases, $\mathrm{M}-\mathrm{X} \cdots \mathrm{X}-\mathrm{M}$, is not expected to be attractive, and can only be considered to be a close contact. Similar close contacts have been reported between dimeric $\mathrm{Pd}_{2} \mathrm{I}_{6}{ }^{2-}$ anions ${ }^{19}$ and between $\mathrm{TlI}_{4}{ }^{-}$anions. ${ }^{20}$

Comparison of motifs 1 and 2 with previously reported motifs. Motif C, as predicted in Fig. 1, is not obtained in any of the structures. In the observed motifs one ammonium group acts as a hydrogen bonding donor to two different anions, instead of two different ammonium groups, as predicted in motif C. In addition, in the observed motifs aromatic interactions do not link cations in a tetramer, but rather link neighbouring zero-dimensional motifs to form a one-dimensional chain. Motifs 1 and 2 are robust since they are maintained in going from structure type I to structure type II, and across a family of isostructural compounds when the ligands and central metal atoms are changed along the $\mathrm{d}^{10}$ metal series.

More general representations of motifs 1 and 2 are shown in Fig. $4 \mathrm{c}$ and $\mathrm{d}$, where a generic cation containing two hydrogen atoms is involved in the tetramer formation. It can now be seen from the general representation of motif 1 that it is, in fact, related to motifs A and B shown in Fig. 1.

Occurrence of motifs in related structures. A Cambridge Structural Database (CSD) search (Version 5.31, August 2010 update) was conducted to find structures containing hydrocarbon cations with one or two terminal ammonium groups, and isolated $\mathrm{MX}_{4}{ }^{2-}$ anions, where $\mathrm{M}$ is a divalent metal atom and $\mathrm{X}$ is $\mathrm{Cl}, \mathrm{Br}$ or I. Structures for which hydrogen atoms were not included and which had disordered atoms were discarded. All hydrates, solvates and structures containing isolated halide anions were excluded. For the structures that had more than one entry in the CSD, only the structure with the lowest $R$ value was

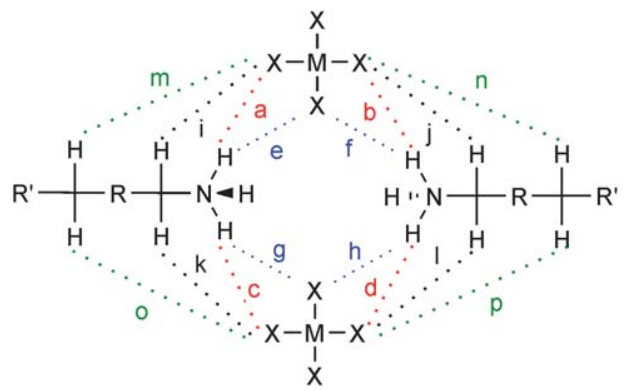

(a)

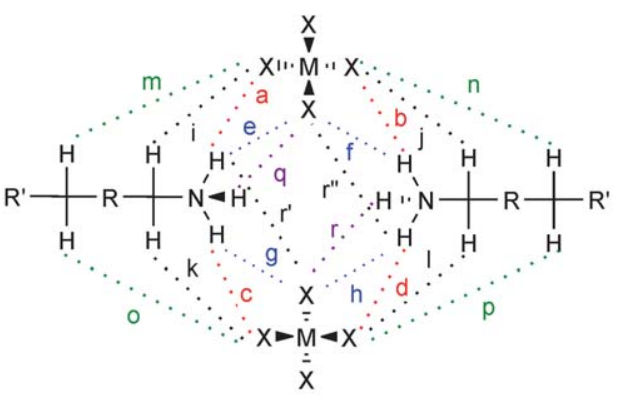

(b)

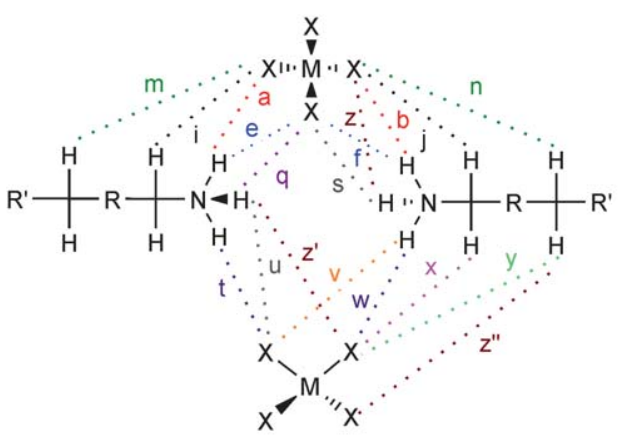

(c)

Fig. 9 Potential hydrogen bonding interactions based on motif 1, motif 2 and other weak interactions in (a) square planar systems, (b) tetrahedral systems, and (c) tetrahedral system with one of the anions rotated relative to the other. Interactions "abcd" form motif 1 in red; interactions "efgh" form motif 2 in blue, and interactions "ijklmnop" are potential weak $\mathrm{C}-\mathrm{H} \cdots \mathrm{X}$ interactions. 


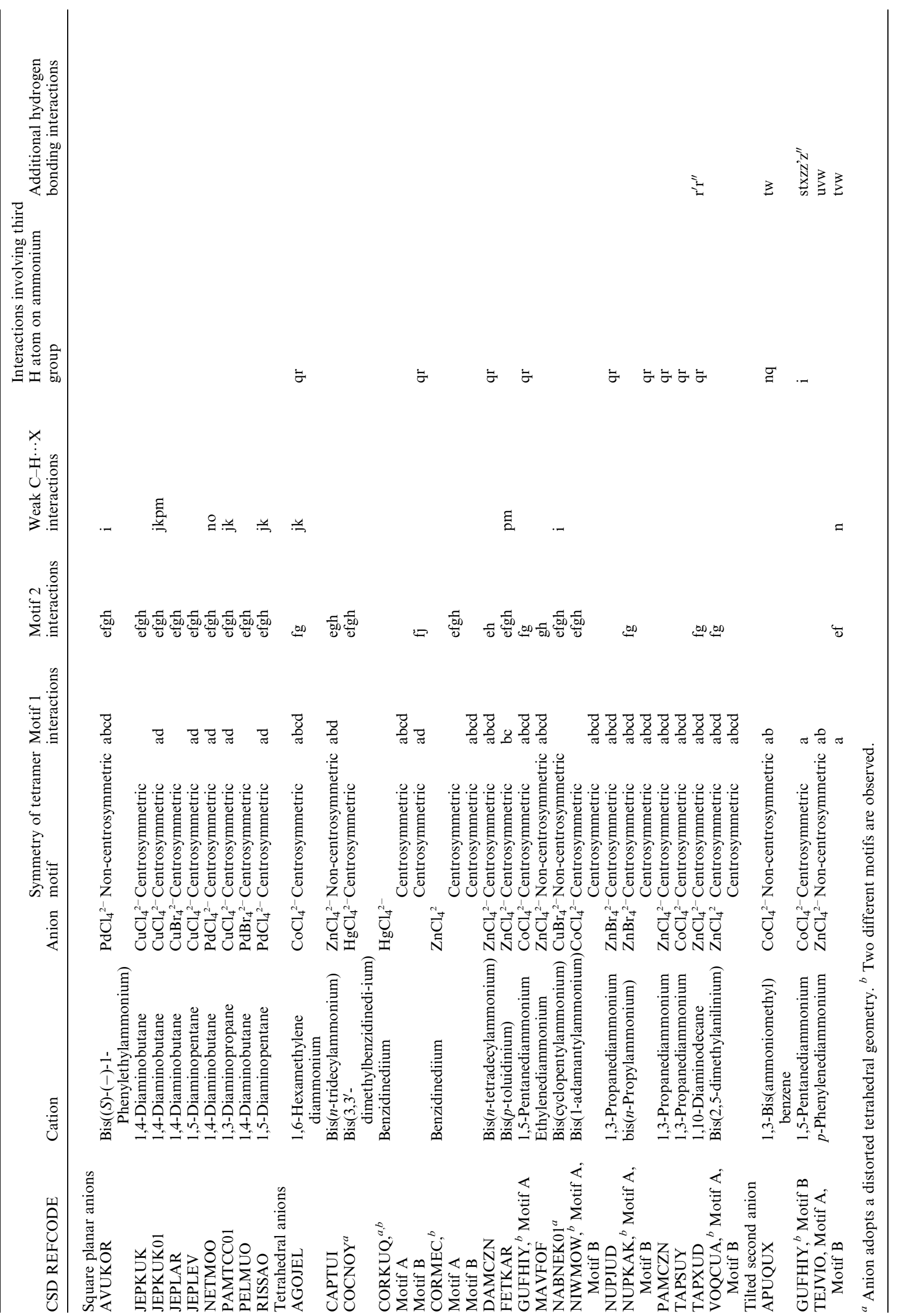


considered. One structure (refcode: LIMXEK) in which the ammonium group was probably incorrectly assigned as a methyl group was discarded. The structures JEPKUK and JEPKUK01 differ in cation geometry, hence they are different conformational polymorphs, and both were included in the motif analysis. A total of twenty-nine unique structures were found, of which nine displayed a square planar anion geometry, ${ }^{21}$ seventeen exhibited a tetrahedral anion geometry ${ }^{22}$ and three showed a distorted tetrahedral anion geometry. ${ }^{23}$

An analysis of the hydrogen bonding interactions occurring in the structures from the CSD search was performed, employing the same spacial orientation used previously, to identify the zerodimensional motifs present. All twenty-nine structures exhibit zero-dimensional motifs related to either motif 1 or motif 2 , or both. This further confirms the robustness of the two motifs, and indicates their potential use as strong directing interactions in crystal engineering.

A number of $\mathrm{N}^{+}-\mathrm{H} \cdots \mathrm{X}^{-}-\mathrm{M}$ and $\mathrm{C}-\mathrm{H} \cdots \mathrm{X}^{-}-\mathrm{M}$ interactions may potentially occur when two ammonium groups and two tetrahalometallate anions of square planar or tetrahedral geometry are positioned in a crystal in the approximate relative spatial relationships observed in motifs 1 and 2, as shown in Fig. 9. The zero-dimensional motifs of the structures found in the CSD search were analysed according to this scheme, and the results are summarised in Table 4, and illustrated in Fig. S3 and $\mathrm{S} 4 \uparrow$.

In the subset of structures with square planar anions the third hydrogen atom on the ammonium group is not involved in hydrogen bonding in any of the zero-dimensional motifs. Motif 2 interactions "efgh" occur in all of the zero-dimensional motifs in this subset, while additional motif 1 interactions are observed in certain structures. Five of the square planar anion containing structures (JEPKUK01, JEPLEV, NETMOO, PAMTCC01, RISSAO) exhibit interactions "ad" in addition to the motif 2 interactions. Of the gauche alkyldiammonium containing structures, only NETMOO shows a weak $\mathrm{C}-\mathrm{H} \cdots \mathrm{Cl}-\mathrm{Pd}$ interaction that may partly account for the deviation from the ideal all-trans geometry. However, this type of interaction may in fact also be present for the rest of the gauche structures, illustrating the difficulty in selecting a suitable hydrogen bond definition and cut-off range. A hydrogen bond is, as stated by Desiraju, an "interaction without a border". ${ }^{24}$ If a more intuitive hydrogen bonding definition is adopted, the rest of the gauche structures may also be considered to show the weak interaction.

In the case of the tetrahedral anion containing structures, the motifs are more complex compared to those identified for the square planar group of structure, but they are still related to motif 1 and motif 2 , and can be divided into two categories. In the first the relative spatial orientation of the two tetrahedral anions and two ammonium groups is similar to that observed in motif 1 and motif 2, while in the second set one of the tetrahedral anions is rotated relative to the other.

In the first tetrahedral subset only two hydrogen atoms per ammonium group form hydrogen bonding interactions in the structures CAPTUI, COCNOY, CORKUQ A and B, CORMEC $A$ and B, FETKAR, MAVFOF, NABNEK01, NIWMOW A and $\mathrm{B}$, NUPKAK $\mathrm{A}$ and $\mathrm{B}$ and TEJVIO $\mathrm{A}$ and $\mathrm{B}$, as observed for the 2-phenylethylammonium tetrahalometallates, while all three hydrogen atoms are involved in hydrogen bonding in the rest of the structures.
The same centrosymmetric motif consisting of interactions "abcdqr" is observed for the shorter chain diammonium structures PAMCZN, TAPSUY, NUPJUD and NUPKAK B, while MAVFOF shows a non-centrosymmetric motif. AGOJEL, GUFHIY A and TAPXUD show the centrosymmetric motif "abcdfgqr" and DAMCZN exhibits interactions "abcdehqr", but CAPTUI exhibits a non-centrosymmetric motif "abdegh".

In the second tetrahedral subset weak $\mathrm{C}-\mathrm{H} \cdots \mathrm{X}^{-}-\mathrm{M}$ interactions are present, which may account for the rotation of one of the anions.

In summary, 21 out of 26 motifs identified for the tetrahedral anion containing structures from the CSD search show the relative orientation of cations and anions as well as strong hydrogen bonding interactions present in either of the two motifs identified for the novel structures in this study, or a combination of the interactions. In addition a number of weak hydrogen bonding interactions may be present.

\section{Conclusions}

In the current series of eleven 2-phenylethylammonium tetrahalometallate structures, seven are classified as structure type I, while two fall in the structure type II category, and both metal and ligand size appear to affect the structure type exhibited by the specific compound, since structure type II is only displayed where the anions consist of the larger metals $(\mathrm{Cd}$ or $\mathrm{Hg})$ and iodo ligands. Structure 2phenZnI, 3, appears to be a borderline case in the structure type I category since its isostructurality parameters differ significantly from the rest of the structures in structure type I.

The 2-phenylethylammonium cation may be distorted to achieve stabilisation through the formation of additional weak hydrogen bonding interactions, as observed in structure 1 where $\mathrm{C}-\mathrm{H} \cdots \mathrm{Cl}-\mathrm{Zn}$ interactions are present, and in structures $\mathbf{6}$ and $\mathbf{9}$ which show weak $\mathrm{C}-\mathrm{H} \cdots \mathrm{I}-\mathrm{M}$ interactions. Distortion from the ideal geometry is also observed in certain $n$-alkyldiammonium containing structures reported in the literature, where cations are distorted from their ideal all-trans geometry by the formation of weak hydrogen bonds.

Two robust zero-dimensional motifs were identified in structures $1,3,5,6,8,9,10$ and 11 . In addition, it was shown that motifs equivalent or related to motifs 1 and 2 occur in 26 out of 29 related structures in the literature, both for isolated square planar and isolated tetrahedral anion geometries with divalent metal atoms $\mathrm{Pd}, \mathrm{Cu}, \mathrm{Co}, \mathrm{Zn}, \mathrm{Cd}$ and $\mathrm{Hg}$ and halogeno ligands chloro, bromo and iodo. The motifs are robust across a range of different organic ammonium cations, including alkyl ammonium-, alkyldiammonium- and both saturated and aromatic cyclic ammonium cations. Based on this robustness across a range of organic ammonium tetrahalometallates it is clear that motifs 1 and 2 can be applied as robust supramolecular synthons in structure design in the field of crystal engineering.

\section{Experimental}

\section{Synthesis}

2-Phenylethylammonium chloride, bromide and iodide salts were prepared by the dropwise addition of excess $\mathrm{HCl}(8.2 \mathrm{ml}, 0.086$ mol, 37\%, Aldrich), $\mathrm{HBr}(8.0 \mathrm{ml}, 0.071 \mathrm{~mol}, 48 \%$, Fluka) or HI 
(12 ml, $0.066 \mathrm{~mol}, 47 \%$ stabilised with phosphoric acid) respectively to a solution of 2-phenylethylamine $(4.8 \mathrm{ml}, 0.040 \mathrm{~mol}$, $99 \%$, Aldrich) in chloroform (20 ml, 99\%, Saarchem). Partial or complete evaporation of the solvent yielded the salts as precipitates which were filtered off and dried in air under vacuum. Crystals were obtained by slow evaporation of an aqueous solution of the 2-phenylethylammonium salt and metal halide salt at room temperature in a $2: 1$ stoichiometric ratio.

$\left(\mathbf{C}_{\mathbf{8}} \mathbf{H}_{9} \mathrm{NH}^{+}{ }_{3}\right)_{\mathbf{2}} \mathbf{Z n C l}_{4}{ }^{2-}$, 1. $0.50 \mathrm{~g}$ of 2-phenylethylammonium chloride $(0.0032 \mathrm{~mol})$ and $0.88 \mathrm{~g}$ of $\mathrm{ZnCl}_{2}(0.0065 \mathrm{~mol}, 96 \%$, Saarchem) were dissolved in a vial in $20 \mathrm{ml}$ distilled water, with the vial left open to the air. Evaporation of the water at room temperature yielded colourless crystals.

$\left(\mathrm{C}_{\mathbf{8}} \mathrm{H}_{\mathbf{9}} \mathrm{NH}_{3}{ }^{+}\right)_{2} \mathrm{ZnI}_{4}{ }^{2-}$, 3. $0.50 \mathrm{~g}$ of 2-phenylethylammonium iodide $(0.0020 \mathrm{~mol})$ and $1.30 \mathrm{~g}$ of $\mathrm{ZnI}_{2}(0.0041 \mathrm{~mol}, 98 \%$, Aldrich) were dissolved in $25 \mathrm{ml}$ distilled water in a vial left open to the air. Solvent evaporation at room temperature gave colourless crystals.

$\left(\mathrm{C}_{8} \mathrm{H}_{9} \mathrm{NH}_{3}{ }^{+}\right)_{2} \mathrm{CdBr}_{4}{ }^{2-}$, 5. $0.50 \mathrm{~g}$ of 2-phenylethylammonium bromide $(0.0025 \mathrm{~mol})$ and $1.73 \mathrm{~g}$ of $\mathrm{CdBr}_{2} \cdot 4 \mathrm{H}_{2} \mathrm{O}(0.0050 \mathrm{~mol}$, $98 \%$, Aldrich) were dissolved in $25 \mathrm{ml}$ distilled water in a vial left open to the atmosphere at room temperature. Evaporation gave colourless crystals.

$\left(\mathbf{C}_{\mathbf{8}} \mathbf{H}_{\mathbf{9}} \mathbf{N H}_{3}{ }^{+}\right)_{\mathbf{2}} \mathbf{C d I}_{4}, \quad 6.0 .50 \mathrm{~g}$ of 2-phenylethylammonium iodide $(0.0020 \mathrm{~mol})$ and $1.50 \mathrm{~g} \mathrm{CdI}_{2}(0.0041 \mathrm{~mol}, 99 \%$, Aldrich $)$ were dissolved in $30 \mathrm{ml}$ distilled water in a vial left open at room temperature. Crystallization yielded light yellow crystals.

$\left(\mathrm{C}_{8} \mathrm{H}_{9} \mathrm{NH}_{3}{ }^{+}\right)_{2} \mathrm{HgBr}_{4}{ }^{2-}$, 8. $0.50 \mathrm{~g}$ of 2-phenylethylammonium bromide $(0.0025 \mathrm{~mol})$ and $1.80 \mathrm{~g}$ of $\mathrm{HgBr}_{2}(0.0050 \mathrm{~mol}, 98 \%$ Sigma Aldrich) were dissolved in $30 \mathrm{ml}$ distilled water in an open vial at room temperature. Evaporation of the distilled water gave colourless crystals.

$\left(\mathrm{C}_{8} \mathrm{H}_{9} \mathrm{NH}_{3}{ }^{+}\right)_{2} \mathrm{HgI}_{4}{ }^{2-}$, 9. $0.50 \mathrm{~g}$ of 2-phenylethylammonium iodide $(0.002 \mathrm{~mol})$ and $1.80 \mathrm{~g}$ of $\mathrm{HgI}_{2}(0.0039 \mathrm{~mol}, 99 \%$, SigmaAldrich) were dissolved in $30 \mathrm{ml}$ of distilled water. Crystallization yielded light yellow crystals.

$\left(\mathrm{C}_{\mathbf{8}} \mathrm{H}_{9} \mathrm{NH}_{3}{ }^{+}\right)_{2} \mathrm{ZnCl}_{2} \mathrm{BrI}^{2-}, \quad 10$. $0.50 \quad \mathrm{~g}$ of 2-phenylethylammonium chloride $(0.0032 \mathrm{~mol}), 0.36 \mathrm{~g}$ of $\mathrm{ZnBr}_{2}(0.0016$ mol, 98\%, Sigma-Aldrich) and $0.51 \mathrm{~g}$ of $\mathrm{ZnI}_{2}(0.0016 \mathrm{~mol}, 98 \%$, Aldrich) were dissolved in $25 \mathrm{ml}$ of distilled water in a vial and left open at room temperature. Solvent evaporation yielded very light yellow crystals.

\section{X-ray structure analysis}

All X-ray diffraction data were collected at room temperature using graphite monochromated Mo $\mathrm{K} \alpha$ radiation. Room temperature X-ray diffraction data for structures 1, 6 and $\mathbf{1 0}$ were collected on an Oxford Diffraction Excalibur 2 CCD diffractometer with a CCD area detector, using $\omega$-scans and the programme CrysAlis CCD $170 .{ }^{25}$ Data reduction was done using
CrysAlis RED $170,{ }^{25}$ and absorption corrections were performed using the multi-scan method. ${ }^{26}$

Intensity data for structures $\mathbf{3}$ and $\mathbf{9}$ were collected on a Bruker SMART 1K CCD diffractometer with an area detector using $\varphi$ and $\omega$-scans. Data reduction was performed using the software SAINT,$+{ }^{27}$ and absorption corrections were made using face indexing with the program XPREP. ${ }^{27} \mathrm{X}$-ray diffraction data for structures 5 and $\mathbf{8}$ were collected on a Bruker SMART APEX II CCD diffractometer employing $\omega$-scans, and data reduction was performed using the software SAINT. ${ }^{28}$ Absorption corrections were performed using SADABS. ${ }^{29}$ All the crystal structures were solved by direct methods using SHELXS-97, ${ }^{30}$ and refined with SHELXL- $97^{30}$ as part of the WinGX ${ }^{31}$ programme suite. Nonhydrogen atoms were first refined isotropically followed by anisotropic refinement by full matrix least-squares calculations based on $F^{2}$ using SHELXL-97. ${ }^{30}$ Hydrogen atoms were positioned geometrically and allowed to ride on their respective parent atoms. Graphics and publication material were generated using ORTEP, ${ }^{32}$ PLATON, ${ }^{33}$ Mercury $2.2^{16}$ and MDL ISIS/ Draw. ${ }^{34}$ CCDC reference numbers 791566-791572.

\section{Acknowledgements}

M.R. acknowledges funding from the University of Pretoria, the University of KwaZulu-Natal and the National Research Foundation (GUN: 2054350). Professor Guy Orpen at the School of Chemistry, University of Bristol is thanked for providing the infrastructure for some of the data collections. We are indebted to Dr M. Fernandes for assisting in the modeling of disorder in structure 9. Thanks to Dr L. Fábián and Prof. A. Kálmán for providing the software to perform the isostructurality calculations.

\section{References}

1 D. B. Mitzi, IBM J. Res. Dev., 2001, 45, 29-45.

2 D. B. Mitzi, Inorg. Chem., 2000, 39, 6107-6113; D. B. Mitzi, J. Chem. Soc., Dalton Trans., 2001, 1-12.

3 V. N. Serezhkin, L. B. Serezhkina, A. S. Ulanov and O. A. D'yachenko, Crystallogr. Rep., 2001, 46, 425-434; V. N. Serezhkin, L. B. Serezhkina and L. M. Bakhmet'eva, Russ. J. Inorg. Chem., 2000, 3, 424 433.

4 P. C. Crawford, A. L. Gillon, J. Green, A. G. Orpen, T. J. Podesta and S. V. Pritchard, CrystEngComm, 2004, 6, 419-428; G. R. Desiraju, Chem. Commun., 1997, 1475-1482.

5 See for example: C. J. Adams, M. F. Haddow, M. Lusi and A. G. Orpen, CrystEngComm, 2011, DOI: 10.1039/C0CE00020E; A. L. Gillon, A. G. Orpen, J. Starbuck, X. Wang, Y. RodriquezMartin and C. Ruiz-Perez, Chem. Commun., 1999, 2287-2288.

6 See for example: C. J. Adams, A. Angeloni, A. G. Orpen, T. J. Podesta and B. Shore, Cryst. Growth Des., 2006, 6, 411-422; C. J. Adams, M. F. Haddow, R. J. I. Hughes, M. A. Kurawa and A. G. Orpen, Dalton Trans., 2010, 39, 3714-3724; C. J. Adams, M. A. Kurawa and A. G. Orpen, Inorg. Chem., 2010, 49, 1047510485; A. Angeloni, P. Crawford, A. G. Orpen, T. J. Podesta and B. J. Shore, Chem.-Eur. J., 2004, 10, 3783-3791; A. Angeloni and A. G. Orpen, Chem. Commun., 2001, 343-344.

7 L. Brammer, J. K. Swaringen, E. A. Bruton and P. Sherwood, Proc. Natl. Acad. Sci. U. S. A., 2002, 99, 4956-4961; G. M. Espallargas, L. Brammer, D. R. Allan, C. R. Pulham, N. Robertson and J. E. Warren, J. Am. Chem. Soc., 2008, 130, 9058-9071; G. M. Espallargas, J. van der Streek, P. Fernandes, A. J. Florence, M. Brunelli, K. Shankland and L. Brammer, Angew. Chem., Int. Ed., 2010, 49, 8892-8896.

8 C. J. Adams, H. M. Colquhoun, P. C. Crawford, M. Lusi and A. G. Orpen, Angew. Chem., Int. Ed., 2007, 46, 1124-1128; 
C. J. Adams, A. L. Gillon, M. Lusi and A. G. Orpen, CrystEngComm, 2010, 12, 4403-4409; A. L. Gillon, G. R. Lewis, A. G. Orpen, S. Rotter, J. Starbuck, X. Wang, Y. Rodriguez-Martin and C. Ruiz-Perez, J. Chem. Soc., Dalton Trans., 2000, 3897-3905.

9 A. Luque, J. Sertucha, O. Castillo and P. Roman, New J. Chem., 2001, 25, 1208-1214; M. Felloni, P. Hubberstey, C. Wilson and M. Schroder, CrystEng Comm, 2004, 6, 87-95.

10 M. Groh, R. Spengler, H. Burzlaff, F. Zouari and A. Ben Salah, Acta Crystallogr., Sect. C: Cryst. Struct. Commun., 1997, C53, 1199-1201.

11 M. Rademeyer, D. G. Billing and A. Lemmerer, Acta Crystallogr. Sect. E: Struct. Rep. Online, 2006, E62, m1716-m1718.

12 Y. Huh, J. H. Kim, S. S. Kweon, W. Kuk, C. Hwang, J. Hyun, Y. Kim and Y. Park, Curr. Appl. Phys., 2006, 6, 219-233.

13 F. Zouari and A. Ben Salah, Solid State Sci., 2004, 6, 847-851.

14 L. Fábián and A. Kálmán, Acta Crystallogr., Sect. B: Struct. Sci., 1999, B55, 1099-1108.

15 J. S. Rutherford, Acta Chim. Hung., 1997, 134, 395-405.

16 I. J. Bruno, J. C. Cole, P. R. Edgington, M. K. Kessler, C. F. Macrae, P. McCabe, J. Pearson and R. Taylor, Acta Crystallogr., Sect. B: Struct. Sci., 2002, B58, 389-397.

17 T. Ueda, M. Omo, K. Shimizu, H. Ohki and T. Okuda, $Z$. Naturforsch., A: Phys. Sci., 1997, 52a, 502-508; J. J. Urban, C. W. Cronin, R. R. Roberts and G. R. Famini, J. Am. Chem. Soc., 1997, 119, 12292-12299.

18 G. R. Desiraju and R. Parthasarathy, J. Am. Chem. Soc., 1989, 111, 8725-8726; L. Brammer, E. A. Bruton and P. Sherwood, Cryst. Growth Des., 2001, 1, 277-290; L. Brammer, G. M. Espallargas and H. Adams, CrystEngComm, 2003, 5, 343-345; F. Zordan and L. Brammer, Cryst. Growth Des., 2006, 6, 1374-1379; F. Zordan, G. M. Espallargas and L. Brammer, CrystEngComm, 2006, 8, 425-431.

19 F. Neve and A. Crispini, CrystEngComm, 2003, 5, 265-268.

20 M. A. Beno, U. Geiser, K. L. Kostka, H. H. Wang, K. S. Webb, M. A. Firestone, K. D. Carlson, L. Nunez, M.-H. Whangbo and J. M. Williams, Inorg. Chem., 1987, 26, 1912-1920.

21 AVUKOR: S. Cruz-Cruz, M. Rodriguez-Pastrana, S. Bernes and R. Gutierrez-Perez, Acta Crystallogr., Sect. E: Struct. Rep. Online, 2004, E60, m342-344, JEPKUK, JEPLAR and JEPLEV: J. K. Garland, K. Emerson and M. R. Pressprich, Acta Crystallogr., Sect. C: Cryst. Struct. Commun., 1990, C46, 16031609, JEPKUK01 and NETMOO: T. Maris, G. Bravic, N. B. Chanh, J. M. Leger, J. C. Bissey, A. Villesuzanne, R. Zouari and A. Daoud, J. Phys. Chem. Solids, 1996, 57, 1963-1975, PAMTCC: G. Zhang, R.-L. Zhang, J.-S. Zhao, X. Gao, S.K. Wang and S.-Y. He, Chin. J. Chem., 2004, 22, 899-902, PELMUO: R. Zouari, J. M. Leger, T. Maris and N. B. Chanh, Acta Crystallogr., Sect. C: Cryst. Struct. Commun., 1998, C54, 1253-1255, RISSAO: T. Maris, Acta Crystallogr., Sect. E: Struct. Rep. Online, 2008, E64, m208.

22 AGOJEL: A. H. Mahmoudkhani and V. Langer, Acta Crystallogr., Sect. E: Struct. Rep. Online, 2002, E58, m592-m594, APUQUX:
S. Haddad, A. Vij and R. D. Willett, J. Chem. Crystallogr., 2003, 33, 245-251, CAPTUI: F. J. Zuniga and G. Chapuis, Acta Crystallogr., Sect. B: Struct. Sci., 1983, B39, 620-325, CORMEC: L. Dobrzycki and K. Wozniak, J. Mol. Struct., 2009, 921, 18-33, DAMCZN: F. J. Zuniga and G. Chapuis, Cryst. Struct. Commun., 1981, 10, 533-540, FETKAR: M. Rademeyer, Acta Crystallogr., Sect. E: Struct. Rep. Online, 2005, E61, m304-m306, GUFHIY: J. J. Criado, A. Jimenez-Sanchez, F. H. Cano, R. Saez-Puche and E. Rodriguez-Fernandez, Acta Crystallogr., Sect. B: Struct. Sci., 1999, B55, 947-952, MAVFOF: W. T. A. Harrison, Acta Crystallogr., Sect. E: Struct. Rep. Online, 2005, E61, m1951-m1952, NIWMOW: H.-M. Guo, H.-Q. Li, G.L. Zhao and S. W. Ng, Acta Crystallogr., Sect. E: Struct. Rep. Online, 2008, E64, m415, NUPJUD and NUPKAK: H. Ishihara, S. Dou, K. Horiuchi, H. Paulus, H. Fuess and A. Weiss, $Z$. Naturforsch., A: Phys. Sci., 1997, 52, 550-560, PAMCZN: A. Kallel, J. Fail, H. Fuess and A. Daoud, Acta Crystallogr., Sect. B: Struct. Sci., 1980, B36, 2788-2790, TAPSUY: N. Guo, Y.-H. Lin, G.-F. Zeng and S.-Q. Xi, Acta Crystallogr., Sect. C: Cryst. Struct. Commun., 1992, C48, 542-543, TAPXUD: N. Guo, Y.-H. Lin, G.-F. Zeng and S.-Q. Xi, Acta Crystallogr., Sect. C: Cryst. Struct. Commun., 1992, C48, 650-652, TEJVIO: J. F. Bringley and M. Rajeswaran, Acta Crystallogr., Sect. E: Struct. Rep. Online, 2006, E62, m1304-m1305; F. J. Zuniga and G. Chapuis, Acta Crystallogr., Sect. B: Struct. Sci., 1983, B39, 620-325, VOQCUA: S. Souissi, W. Smirani and M. Rzaigui, Acta Crystallogr., Sect. E: Struct. Rep. Online, 2009, E65, m442.

23 COCNOY: L. Dobrzycki and K. Wozniak, CrystEngComm, 2008, 10, 525-533, CORKUQ: L. Dobrzycki and K. Wozniak, J. Mol. Struct., 2009, 921, 18-33, NABNEK01: R. D. Willett, C. Galeriu, C. P. Landee, M. M. Turnbull and B. Twamley, Inorg. Chem., 2004, 43, 3804-3811.

24 G. R. Desiraju, Acc. Chem. Res., 2002, 35, 565-573.

25 Oxford Diffraction Ltd, CrysAlis CCD and CrysAlis RED, Version 1.170, Oxford Diffraction Ltd, Abingdon, Oxford, England, 2003.

26 R. H. Blessing, Acta Crystallogr., Sect. A: Found. Crystallogr., 1995, A51, 33-38.

27 Bruker SAINT+, V6.02 (including XPREP), Bruker AXS Inc., Madison, WI, USA.

28 Bruker SAINT V6.28A, Bruker AXS Inc., Madison, WI, USA.

29 G. M. Sheldrick, SADABS: A Program for Absorption Correction with the Siemens SMART System, University of Göttingen, Germany, 1996.

30 G. M. Sheldrick, SHELXS97 and SHELXL97, University of Göttingen, Germany, 1997.

31 L. J. Farrugia, J. Appl. Crystallogr., 1999, 32, 837-838.

32 L. J. Farrugia, J. Appl. Crystallogr., 1997, 30, 565.

33 A. L. Spek, J. Appl. Crystallogr., 2003, 36, 7-13.

34 MDL ISIS Draw 2.5, MDL Information Systems, Inc. 